\title{
IMPROVING THE DELIVERY OF SOCIAL PROTECTION THROUGH ICT CASE STUDIES IN MONGOLIA, NEPAL, AND VIET NAM
}

Sri Wening Handayani, Michelle Domingo-Palacpac, Clifford Chi Burkley, and Peter Lovelock

NO. 50

November 2017

\section{ADB SUSTAINABLE DEVELOPMENT WORKING PAPER SERIES}


Sustainable Development Working Paper Series

\section{Improving the Delivery of Social Protection through ICT-Case Studies in Mongolia, Nepal, and Viet Nam}

Sri Wening Handayani,

Michelle Domingo-Palacpac,

Peter Lovelock, and Clifford Chi Burkley

No. 50 | November 2017
Sri Wening Handayani is principal social development specialist in ADB's Sustainable Development and Climate Change Department (SDCC).

Michelle Domingo-Palacpac is senior operations coordination officer in ADB's SDCC.

Clifford Chi Burkley is an independent consultant, with specialization in social protection, and community-driven development.

Peter Lovelock is director of the Technology Research Project Corporate (TRPC), an IT and telecommunication-based think-tank with offices across Asia. He was ICT consultant for ADB's technical assistance project on the role of ICT in social protection. 
(c) 2017 Asian Development Bank

6 ADB Avenue, Mandaluyong City, 1550 Metro Manila, Philippines

Tel +632632 4444; Fax +6326362444

www.adb.org

Some rights reserved. Published in 2017.

Printed in the Philippines.

Publication Stock No. WPS179135-2

DOI: http://dx.doi.org/10.22617/WPS179135-2

The views expressed in this publication are those of the authors and do not necessarily reflect the views and policies of the Asian Development Bank (ADB) or its Board of Governors or the governments they represent.

ADB does not guarantee the accuracy of the data included in this publication and accepts no responsibility for any consequence of their use. The mention of specific companies or products of manufacturers does not imply that they are endorsed or recommended by ADB in preference to others of a similar nature that are not mentioned.

By making any designation of or reference to a particular territory or geographic area, or by using the term "country" in this document, $A D B$ does not intend to make any judgments as to the legal or other status of any territory or area.

This work is available under the Creative Commons Attribution 3.0 IGO license (CC BY 3.0 IGO) https://creativecommons.org/licenses/by/3.0/igo/. By using the content of this publication, you agree to be bound by the terms of this license. For attribution, translations, adaptations, and permissions, please read the provisions and terms of use at https://www.adb.org/terms-use\#openaccess

This CC license does not apply to non-ADB copyright materials in this publication. If the material is attributed to another source, please contact the copyright owner or publisher of that source for permission to reproduce it. ADB cannot be held liable for any claims that arise as a result of your use of the material.

Please contact pubsmarketing@adb.org if you have questions or comments with respect to content, or if you wish to obtain copyright permission for your intended use that does not fall within these terms, or for permission to use the ADB logo.

Note:

Corrigenda to ADB publications may be found at http://www.adb.org/publications/corrigenda 


\section{CONTENTS}

FIGURES AND BOXES

ACKNOWLEDGMENTS

EXECUTIVE SUMMARY Vi

$\begin{array}{ll}\text { I. INTRODUCTION } & 1\end{array}$

II. DEVELOPMENTS IN INFORMATION AND COMMUNICATION TECHNOLOGY FOR SOCIAL PROTECTION (ICT4SP) IN ASIA AND THE PACIFIC

III. PROGRESS AND CHALLENGES IN DEVELOPING ICT4SP: CASE STUDIES IN MONGOLIA, NEPAL, AND VIET NAM
A. Progress
B. Challenges

IV. COSTS AND BENEFITS OF ICT4SP

A. $\quad$ Supporting Infrastructure $\quad 12$

B. Databases: Transactions versus Operational Analytics $\quad 12$

C. Resource Management 13

V. FUTURE DIRECTIONS FOR ADB IN SUPPORTING DEVELOPMENT OF ICT4SP 15

$\begin{array}{ll}\text { REFERENCES } & 17\end{array}$ 


\section{FIGURES AND BOXES}

\section{FIGURES}

1 Households with Internet Access in Asia and the Pacific, 2016

2 Mobile Money Services 3

3 Households with Mobile/Cellular Phone Subscriptions in Asia and the Pacific, 2016

\section{BOXES}

1 Benefits of Database Use to Integrate Social Protection Services 5

2 Main Challenges in Adopting ICT4SP in Mongolia, Nepal, and Viet Nam 6

3 ICT4SP Taxonomies $\quad 8$

4 Case Study in Viet Nam 10

5 Case Study in Mongolia 11

6 Case Study in Nepal 14 


\section{ACKNOWLEDGMENTS}

This paper was prepared as part of the implementation of the regional technical assistance for Information and Communication Technologies for Social Protection in the Asia and Pacific Region.*

The authors are grateful to consultants John Ure and Kimberly Fullerton for their contribution in putting the report together; to Seok-Yong Yoon, ADB's senior public management specialist in the Sustainable Development and Climate Change Department; and to the members of ADB's Social Development Thematic Group Committee Abid Hussain, Paolo Spantigati, Sakiko Tanaka, Michiel Van der Auwera, and Emma Veve for their inputs to the earlier versions of this paper.

* ADB. 2014. Technical Assistance for Information and Communication Technologies for Social Protection in the Asia and Pacific Region. Manila. 


\section{EXECUTIVE SUMMARY}

The rapid growth of the information and communication technology (ICT) sector over the past 2 decades has been changing the face and pace of development. Many countries in Asia and the Pacific are investing in ICT and integrating its elements in governance, including social protection programs.

ICT integration in social protection is driven by the demand for more accurate and efficient service, from within social protection agencies as well as from the public. ICT automates and improves data management, reducing workloads and enabling managers to make more informed decisions. ICT also provides convenience and faster service as well as better security for beneficiaries and the public.

The need for transparency also drives the move toward ICT integration into social protection programs. In Viet Nam and the Philippines, for example, improvement in database management helped address inclusion and exclusion errors, and allowed for greater transparency in the beneficiary lists of social protection programs.

ICT integration into social protection programs help increase coverage of the programs and empower beneficiaries. Mobile devices such as tablets and smartphones help program staff undertake surveys, record and update information to increase the coverage among poor families. Mobile money allows programs to reach more geographically isolated areas. Nepal's use of cash cards provides an example of mobile solutions in transferring social protection funds to program beneficiaries.

The increasing access of households to internet and mobile-cellular phones in Asia and the Pacific present opportunities for greater integration of ICT applications in implementing social protection programs. However, poor telecommunications and power infrastructure, lack of appreciation for new technology on the part of prospective beneficiaries, and delays in the development of technical standards for the interconnection of networks and interoperability of systems, slow down the incorporation of ICT tools in the region. Additional issues, notably in Mongolia and Viet Nam, are cybersecurity and identity theft.

The Asian Development Bank's (ADB) experience with incorporating ICT in social protection programs, mostly in monitoring and evaluation, suggests that such an integration only entails a small portion of the total program costs. For ADB, there is scope in increasing investments in ICT for social protection by using both lending and nonlending instruments. Country studies suggest that country conditions and preparedness for ICT vary and that ADB should focus on incrementally improving internal processes and administration, including improving database management and financial systems, and reporting. 


\section{INTRODUCTION}

1. The ADB social protection operational plan, 2014-2020 recognizes information and communication technology (ICT) as a potential sector for investment and knowledge work to strengthen social protection programs ${ }^{1}$ in its developing member countries (DMCs). In recent years, with assistance from $A D B$, many DMCs have expanded their social protection programs and developed national social protection strategies.

2. ICT is increasingly enabling policies and strategies to help deliver social protection programs. As the costs of technology fall and availability goes up, information and communication technology for social protection (ICT4SP) is showing gains in efficiency, transparency, and scope of services available. ICT4SP is providing ways to administer, monitor, and evaluate development projects and programs. At the same time, the use of the internet, social media, and broadband wireless communications also empower citizens by opening up areas of information and social engagement that can influence policies and resources devoted to social protection.

3. ICT4SP has, however, been limited, compared to other sectors, such as health, education, and infrastructure. ICT4SP has been widely used for targeting and beneficiary identification, improved payment mechanisms, and identity management. ICT has also been used to re-engineer business processes that have helped administer major social protection programs in various countries.

4. Among the obstacles in the adoption of ICT4SP in Asia and the Pacific are the low appreciation and capacity in many DMCs to maximize benefits from investments in ICT4SP. Knowledge and capacity gaps in DMCs perpetuate the digital divide between developing and developed economies, while infrastructure gaps impede the adoption of ICT4SP, resulting in few resources accorded to these programs.

5. The failure to take advantage of the benefits of ICT4SP has led to continued program leakages, and higher transaction and administration costs. Innovations in ICT, when applied to social protection programs, can help address these issues and present opportunities to increase cost effectiveness and efficiency. ICT can also help expand the reach of social protection programs at lower costs. The use of short message services (SMSs) as a payment tool, for example, is now reaching geographically isolated areas at almost no cost.

6. This study takes stock of recent practices in the use of ICT4SP in some DMCs. Country case studies in Mongolia, Nepal, and Viet Nam showcase technological solutions that can be applied in other DMCs to improve targeting, payments, monitoring, and assessment of social protection programs. These case studies also identify gaps and obstacles on ICT integration into social protection. Although not formally part of the ADB case studies, the experience of the Philippines is also cited in some sections to add information on the topic.

\section{DEVELOPMENTS IN INFORMATION AND COMMUNICATION TECHNOLOGY FOR SOCIAL PROTECTION (ICT4SP) IN ASIA AND THE PACIFIC}

7. ICT has redefined development over the past 20 years, as technological progress and the declining cost of technology have brought unexpected growth in access and connectivity to billions

1 ADB. 2014. Social Protection Operational Plan, 2014-2020. Manila. 
of people around the world. Globally, the International Telecommunications in 2015 estimates that more than 7 billion mobile phone subscriptions exist worldwide, up from less than 1 billion in 2000, and over 3.2 billion people were using the internet by the end of 2015. In addition, an estimated 4 billion people from developing countries remained offline, representing two-thirds of the population in developing countries. Digitalization and intensive use of the internet are experienced in many countries worldwide. On a typical day, 3,000 petabytes ${ }^{2}$ of intellectual property traffic, 500 million photographs, and 22 months of videos per second are accessed and uploaded to the internet. One billion people are on social media, 1.5 million people use mobile devices for the first time, and 183 billion e-mails are sent. ${ }^{3}$

8. In Asia and the Pacific, however, there remains a big gap in terms of access and usage of internet. Based on ITU's data for 2016, the average percentage of households with access to internet at home is 46.4\% (Figure 1) which is way below the average for more development regions like Europe with 84.0\% of households with internet access at home. Only Japan, the Republic of Korea and Singapore are at par with the average of more developed regions, and Azerbaijan, Kazakhstan, Malaysia, and Uzbekistan following closely.

Figure 1: Households with Internet Access in Asia and the Pacific, 2016

$(\%)$

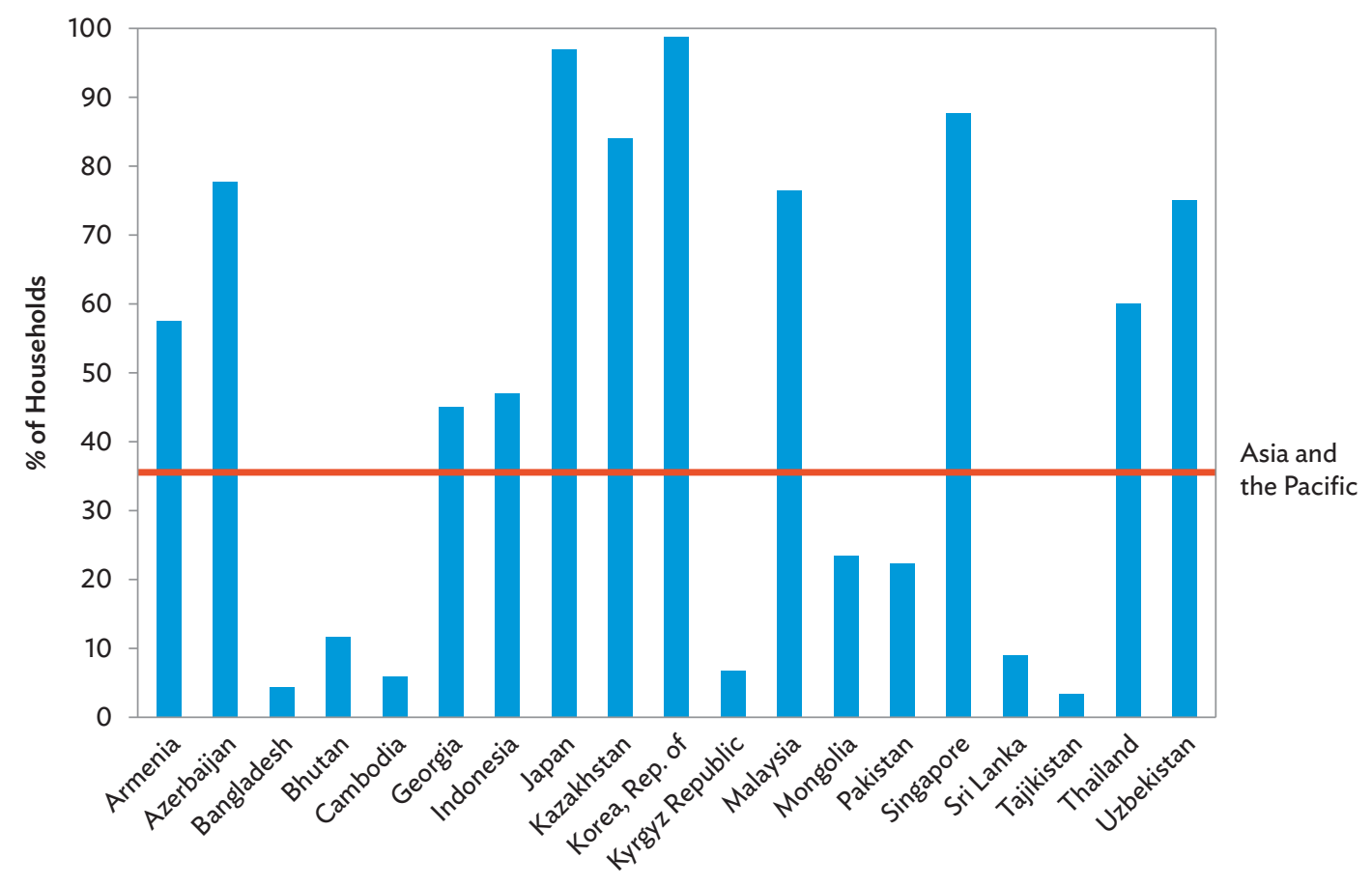

Source: International Telecommunications Union. 2017.

2 To understand the size of a petabyte, it would take 223,000 DVDs (at 4.7 gigabytes each) to hold 1 petabyte. B. McKenna. 2013. What Does a Petabyte Look Like? Computer Weekly.com. http://www.computerweekly.com/feature/What-does-apetabyte-look-like

3 International Telecommunications Union. 2015. 
9. Mobile phones are increasingly being used as financial tools for transferring and receiving funds. This is helping increase access of the unbanked population to financial services which is estimated to be about 2 billion in 2014 globally. Mobile network operators have set up large, low-cost distribution networks to provide cash-in and cash-out services to consumers cheaper than the cost incurred by conventional bank branches or ATMs. Through the subscriber identity module (SIM) card in each phone, mobile phone operators are able to identify users and authenticate transactions, making this technology more appreciated by regulators.

10. Figure 2 provides an example of a mobile payments system based on accounts held by a mobile network operator and accessible from subscribers' mobile phones. There are 255 live mobile services in 89 countries as of December 2014 and 61\% of developing markets where mobile money is now available. The conversion of cash into electronic values (and vice versa) occurs at retail stores, where all transactions are authorized and recorded in real time using secure SMSs.



11. In Asia and the Pacific, an estimated $94.1 \%$ of the population has mobile-cellular subscriptions. Hence, the use of mobile payment solutions presents enormous opportunities to increase access of the unbanked population to financial services. Mobile payment solutions are also increasingly being used in social protection programs in the region. In Pakistan, the Benazir Income Support Program which was launched in 2008 and now the largest social protection program in the country, provides monthly payments/cash grants to beneficiaries through mobile banking have been implemented in five districts on a pilot basis. ${ }^{4}$ Similarly, in the Philippines, GCash (i.e., mobile cash) is provided to beneficiaries on a monthly or quarterly basis through the largest conditional cash transfer (CCT) program in the country. ${ }^{5}$

4 More information is available from http://bisp.gov.pk/

5 CCTs provide direct cash support to beneficiaries, usually poor families, on the condition that they fulfill certain requirements that are normally related to achievement of health, nutrition, and education outcomes. ADB has supported CCTs in Pakistan and the Philippines. 
Figure 3: Households with Mobile/Cellular Phone Subscriptions in Asia and the Pacific, 2016

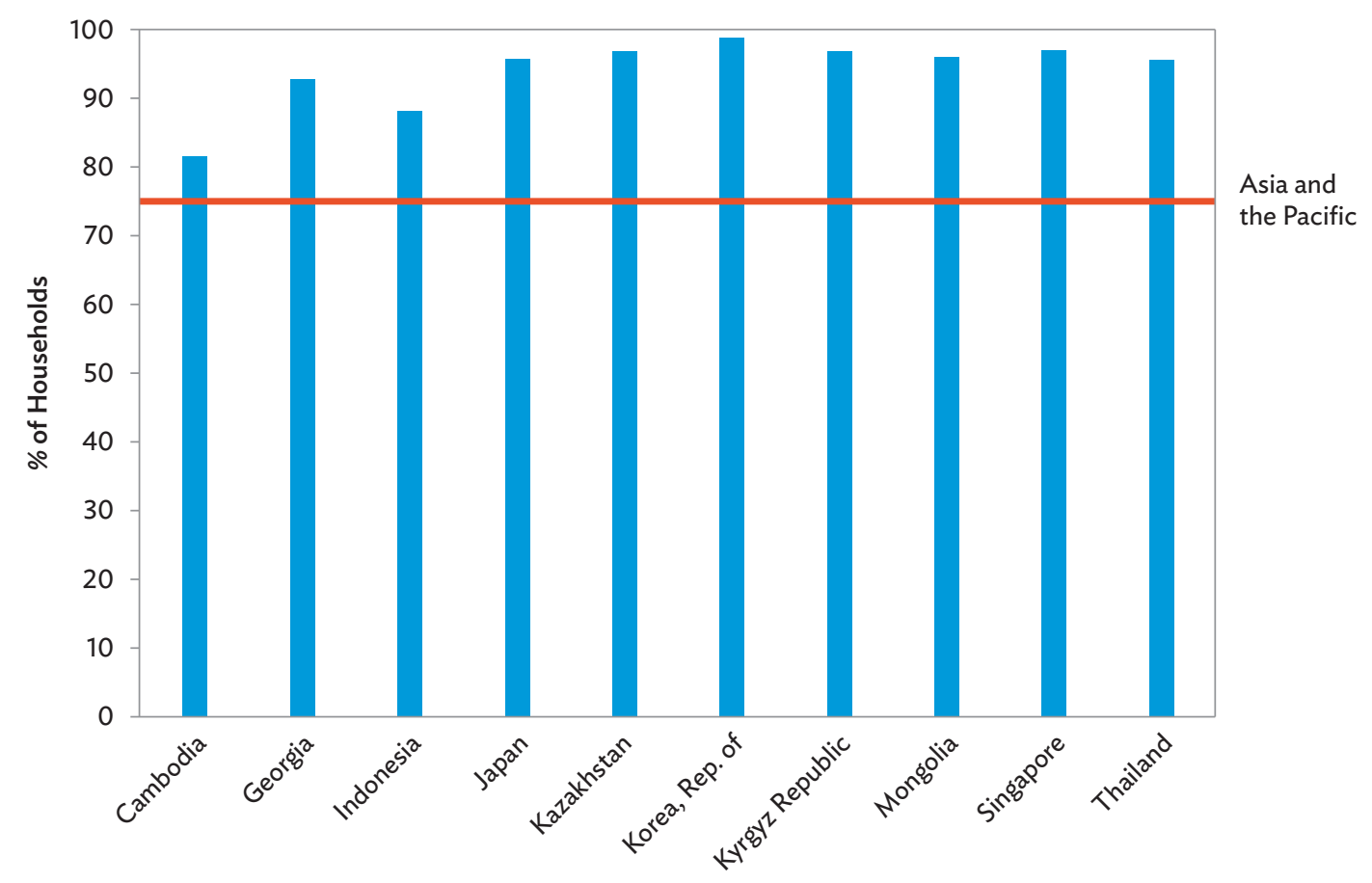

Source: International Telecommunications Union. 2017.

12. In the last decade, ICT4SP has been featured in core business processes, including (i) identification, which denotes the determination of eligibility of beneficiaries, usually through the use of beneficiary-targeting schemes, managed in a database; (ii) beneficiary updates and validation (i.e., continuous maintenance and updating of beneficiaries' lists in a secure database), which usually feeds into and develops benefit computation; (iii) validation of contribution or documentation of compliance or payment and contributions of beneficiaries or members; (iv) actual payments or distribution of benefits; (v) verification of program efficacy or evaluation of performance and impact; and (vi) generation of reports, especially financial performance, at regular intervals.

13. ICT4SP can aid the promotion of efficiency and cost savings via cross-sector collaboration and systems integration, and innovation in the delivery of services to beneficiaries. These initiatives aim to transform how individuals interface with social service providers through the design of integrated approaches, such as electronic user records, data analytics, and interoperable technologies that enable beneficiaries to have a better understanding of service use. ${ }^{6}$

14. The 2015 study by the European Union (footnote 6) finds that using databases to integrate services provided by different ICTs generates benefits to both the administrative side of social protection

6 G. Misuraca, C. Colombo, R. Radescu, and M. Bacigalupo. 2015. ICT-Enabled Social Innovation in Support to the Implementation of the Social Investment Package - IESI. European Commission JRC Science and Policy Report. http:// publications.jrc.ec.europa.eu/repository/bitstream/JRC97467/jrc97467.pdf 
provision and the beneficiaries. Databases are central to the integration process, and desktop and handheld terminals and peripherals all relate back to the databases (Box 1).

\section{Box 1: Benefits of Database Use to Integrate Social Protection Services}

\section{Organizational benefits:}

- Enhances efficiency by reducing costs

- Improves value for money

- Strengthens strategic planning and system integrity

- Lessens need for emergency services

\section{Benefits for recipients:}

- Provides simplified access

- Provides holistic, customized support

- Results in faster response times

- Improves user experience

\section{Benefits of using terminals and peripherals:}

- Informs policy making aided through report generation

- Helps in coherent, consistent policy making across government

- Reduces duplication of database entries and cases of fraudulent entries

- Creates a holistic view of every beneficiary

- Speeds up search and processing, does away with paperwork, and reduces errors

- Enables use of analytics software for estimations, forecasts, and calculations

- Has potential ubiquitous access through secure networks and hybrid or encrypted public clouds

- Can be made interoperable with agency midstream software programs

- Can give partitioned and conditional access to recipients

- Can promote self-service by beneficiaries

Source: G. Misuraca, C. Colombo, R. Radescu, and M. Bacigalupo. 2015. ICT-Enabled Social Innovation in Support to the Implementation of the Social Investment Package - IESI. European Commission JRC Science and Policy Report. http://publications. jrc.ec.europa.eu/repository/bitstream/JRC97467/jrc97467.pdf

\section{PROGRESS AND CHALLENGES IN DEVELOPING ICT4SP: CASE STUDIES IN MONGOLIA, NEPAL, AND VIET NAM}

15. The demand from beneficiaries of social protection programs for accuracy, faster service, and the need to scale up programs provide the push for greater ICT use in program implementation. This involves shifting from traditional paper-based methods that tend to be slow and prone to errors, to electronic means of managing programs. Such shift provides opportunities for program managers to introduce and integrate ICT tools and applications in work processes. However, developing countries face challenges when shifting from traditional forms of service delivery to modern and automated methods. Simplifying workloads through automation ceases to be the main reason for the move toward ICT use but is driven more by the need to increase efficiency in program implementation. 


\section{A. Progress}

16. Some of the enabling factors for faster take-up of ICT in social protection programs are present in Mongolia, Nepal, and Viet Nam. Through an ADB technical assistance, scoping studies were carried out to assess the progress and challenges in further integrating ICT in the design and delivery of social protection programs. ${ }^{7}$

17. With the improvement in Mongolia's ICT infrastructure, integration of ICT in government service delivery is receiving more attention. The government is implementing a series of activities using ICT for e-governance, such as developing e-content, providing online public services to citizens, and allowing use of e-kiosks to access services. A website is used as a portal for communication among citizens, government organizations, and officials to provide inputs, comments, and feedback on policies, draft laws, and regulations, as well as to raise issues and concerns with government. ${ }^{8}$

18. Nepal has embarked on several projects integrating ICT in social service delivery including as part of their post disaster response mechanism. The digitalization of civil registration systems is part of the shift from traditional to an automated system that can be linked to improve beneficiary identification for public service programs including social protection. E-banking and mobile payment facilities are also increasingly used in Mongolia and Nepal.

19. Viet Nam, on the other hand, is among the top three fastest-growing ICT market in Asia and is expected to be among the top ICT spenders in the region. The proliferation of smart-connected devices, use of mobile computing and banking services, and popularity of social networks are creating new opportunities for use of ICT in social protection in Viet Nam.

\section{B. Challenges}

20. Several constraints tend to slow down or block ICT4SP adoption in Asia and the Pacific. These are summarized in Box 2 and discussed in more detail below.

\section{Box 2: Main Challenges in Adopting ICT4SP in Mongolia, Nepal, and Viet Nam}

- Interoperability-requires integration and access across different departments, ministries, and between capital city and provincial centers

- Poor telecommunications infrastructure and limited power supply

- Data and cyber security

- Inadequate budget

- Inadequate technical skills of program staff

- Limited access to financial services

- Need for automation or digitalization at an organizational level

Source: ADB. 2016. Technical Assistance Consultant Reports - ICT for Social Protection.

7 ADB. 2014. Technical Assistance for Information and Communication Technologies for Social Protection in Asia and the Pacific. Manila.

8 See website of Government of Mongolia http://www.zasag.mn/en/ 


\section{Interoperability}

21. Technical standards, which are necessary for the interconnection of networks and the interoperability of systems running different applications, have been introduced only recently. ${ }^{9}$ Interoperability is a key issue in developing countries which requires integration of and access to databases across different departments, ministries, and between a capital city and provincial centers. Such process requires coordination and sharing of data among and between ministries and/or departments. This is also linked to use of integrated targeting database has been applied to several social assistance programs to limit duplication. Integrated databases have enabled report submission through the internet to validate beneficiary compliance with conditions, and thus, their eligibility to receive subsequent payments.

\section{Poor infrastructure}

22. Poor telecommunications infrastructure and limited power supply are other constraints. For example, in Mongolia, where intended beneficiaries are spread over a wide territory, the challenge of setting up ICT infrastructure and unreliable power supply pose significant constraints.

\section{Data and cyber security}

23. Another concern is the issue of security. This has been cited during consultations in Mongolia, Nepal, and Viet Nam as an important factor that delays adoption of automated systems in social protection delivery. Ministries and other government offices implementing social protection programs cited security issues and threats of cyber theft and attack as key stumbling blocks in ICT adoption. These concerns also arise from several recent global cases in which websites have been compromised, exposing personal information for often nefarious purposes.

\section{Inadequate budget}

24. Inadequate budget is also frequently a challenge. Higher costs are associated with back-end ICT investments, in particular databases, and their environment. Indeed, the major trend identified in the literature is the adoption of ICT for the integration of back-end systems, most commonly of databases to be shared and accessed by different units within an agency or across agencies. Creating a fully functional back-end ICT system is complex, however, whether through a traditional structure of networked servers and clients, online access to centralized databases, or virtualized private or hybrid cloud-based architecture. The assistance of both vendors and system integrators is required, especially where software and applications need to be customized to social protection programs.

\section{Inadequate technical skills}

25. As the operations of a program become more automated, the increasing demand of managerial and technical staff in improving service delivery is then highlighted. As an example, the initial focus of ICT4SP in Viet Nam was improvement of internal management procedures and systems that simplified the work of staff and managers in social protection agencies. The need to clean and, later, integrate databases of beneficiaries from various programs to stem leakages and avoid duplication was a key concern requiring enhancing technical skills of program staff or adding new staff who specialize in ICT. As

9 The ISSA guidelines are supplemented by the work of the ICT Technical Commission on Standards, 2014-2016. See ISSA. ISSA Guidelines on Information and Communication Technology. https://www.issa.int/excellence/guidelines/ict 
these concerns were addressed, the use of better payment systems to improve services for beneficiaries became more of a priority.

\section{Limited access to financial services}

26. Payment systems or mechanisms by which beneficiaries receive the cash transfers from social protection programs is a major area where ICT applications can increase efficiency and program effectiveness. However, in the cases of Nepal and Viet Nam, access to financial services remain limited to those in formal employment or in urban/city centers. Those in the peripheral economies lack access to financial services provided through commercial banks and/or mobile banking. Mongolia, on the other hand, has more success in increasing access of its population to financial services. This was done through partnerships with major banks and telecommunications companies.

\section{Need for organizational process change}

27. The adoption of ICT is likely to be part of an organizational process rather than used discretely as stand-alone units. For example, payments may be distributed to beneficiaries with the use of mobile devices, but that requires a back-end process to generate numbers and pass the necessary data to banks or mobile network operators. In the early stages of ICT4SP adoption, an incremental approach is highly likely, by adding to and extending the reach and scope of existing services. The adoption of computers is a first step, followed by the adoption of database software and digital storage and retrieval facilities (i.e., an additive process). Later, when whole systems are upgraded, the process may be thought of as becoming more cumulative (Box 3 ).

\section{Box 3: ICT4SP Taxonomies}

Information and communication technology (ICT) as applied to social protection practices fall into five broad categories of use and impact, often combined:

- Technical or incremental. The use of ICT that automates or replaces manual routines and paperwork with digital technologies, such as the use of stand-alone computers.

- Sustained. The use of ICT that brings about long-term organizational and administrative improvements in efficiency, accuracy, and targeting, such as the use of databases and analytical software programs.

- Disruptive. The use of ICT to bring about a fundamental restructuring in the way that programs are organized, often involving an internal shift of ownership of projects, which could, for instance, result in the merging of government agencies. The integration of databases may be part of this process.

- Radical. The use of ICT that goes beyond disruptive, such as a shift toward greater stakeholder influence through web-based information systems, and the involvement of, or outsourcing to, nongovernment organizations or community associations.

- Transformative. The use of ICTs that is totally radical, producing a wholesale change in the approach toward social protection, such as web-based systems of self-declaration and assessment. Modern taxation systems often move in this direction.

Source: G. Misuraca, C. Colombo, R. Radescu, and M. Bacigalupo. 2015. ICT-Enabled Social Innovation in Support to the Implementation of the Social Investment Package - IESI. European Commission JRC Science and Policy Report. http://publications. jrc.ec.europa.eu/repository/bitstream/JRC97467/jrc97467.pdf 
28. A more disruptive use of ICT involves a change of entire systems and substituting new ways for existing practices. For example, separately defined services and their respective databases can be integrated, so that benefits can be simultaneously calculated and delivered. This may improve the accuracy and timeliness of payments, and provide beneficiaries with a "one-stop shop" web portal to check their status. These changes are disruptive in the sense that they call for parallel changes in organizational and administrative structures and staffing requirements, which need to be managed with foresight. The disruptive adoption of ICT is a process of substitution, with the adoption of new practices replacing previously established practices.

29. Changes in the philosophy underlining the delivery of social protection can also be radical. Such changes may, for example, place greater emphasis upon the direct participation of beneficiaries and their initiative in managing their claims. The ongoing rapid evolution of social media and Web 2.0 technologies, ranging from smartphone applications to collaborative tools for communications and work processing, change the balance of how social protection is organized and delivered. Radical changes (i.e., participatory changes) do not have to impact the entire zone of social protection, however. On the contrary, they may be introduced on a trial basis to different parts of the system, for specific services, or spatially distributed by districts. It is likely that radical adoption of ICT will be heavily reliant on a welldeveloped telecommunications and internet infrastructure, as well as the accessibility and affordability of smart devices.

30. The policy and managerial changes involved in ICT adoption can indeed be difficult and slow to achieve. At the technical level, it is prudent to build ICT systems incrementally, whether they are new systems replacing existing systems. At first, the budget can be more easily controlled, and be more transparent; the achievements are more easily monitored and evaluated. Second, systems should be tested for effectiveness, security, and efficiency, and revisions must be made before they are widely applied. Third, ICT today can change rapidly, so a step-by-step process ensures the manageability of upgrades and continued relevance of a system, especially as additional and next-generation systems are added that need to be backwards-compatible and interoperate with earlier systems. Modular growth and adjustments can be adapted at each stage and level, from back-end to front-end and from the core of the network to applications.

31. Successful ICT innovations are often led from the top, requiring significant ownership and leadership from managers that can shepherd the process of change management. Project management skills are key. Project managers should be able to make critical assessments of architectural designs and their achievability within budgets and timelines, as well as have knowledge of how to source reliable information on ICT proposed for adoption and their operational requirements, such as the need to train staff in ICT skills. Governments may have difficulty in recruiting or retaining fully trained staff if the private sector offers better terms and conditions of employment, such as has been the case in the Philippines. One answer is to outsource, but another is to devote resources to in-house training and boost the number of national graduates with ICT skills.

32. The overall architecture of the system is also important when different agencies and various functions need to be integrated, such as databases for the registration of beneficiaries and software analytics than can identify duplicates and cases of fraud, track changes in the circumstances of beneficiaries, run budgetary estimates, and generate reports.

33. Initial applications are frequently restricted, often for budgetary purposes, to administrative tasks, which can be further restricted to higher levels of administration. Yet, while the focus is on administrative improvement in terms of accuracy and efficiency, it remains possible for some parts of 


\section{Box 4: Case Study in Viet Nam}

Information and communication technology for social protection (ICT4SP) in Viet Nam is in its formative stages. Currently, six different software programs cover areas such as social insurance contributions to record contributions, social protection notebooks and health insurance card software to replace manual data entries of insurance contributions by beneficiaries, benefit determination software, payment software, health and management software, and accounting software. The Viet Nam Social Insurance Agency operates software at 63 provincial offices and 713 district offices, with little integration between them, and there is no nationally standardized user identifier system. Consequently, for example, a child can receive multiple health insurance cards because he or she belongs to several lists of beneficiaries (i.e., under the age of 6 years), and is a relative of a soldier. In 2012-2013, statistics indicated that over 1.3 million duplicate health insurance cards had been issued. In the case of social protection notebooks, there are instances of fraudulent claims, such as a case cited where the beneficiary registered in two different social security offices.

The Viet Nam Social Insurance Agency has begun to replace its six software systems through a 3 management program to cover administrative management, monetary transactions to recipients, and health insurance review software. This will take time, as only 3 of the 63 provinces currently have the new software, and most recipients are still required to visit offices as the service remains offline. Benefits will also be constrained by, for example, the fact that only one-third of households have bank accounts, so the electronic funds transfer enabled by the software covers less than 7\% of recipients. The Ministry of Labor, Invalids and Social Affairs has also introduced a new software program with assistance from the World Bank's Multi-Sectoral Technical Assistance Project. However, the program is not yet online or mandatory for all offices.

Source: ADB. 2016. Regional Technical Assistance 8686 Consultant Report (Viet Nam).

the databases to be open to the public through web-based searches for information, such as checking benefits, making claims, booking appointments, or changing a status or other demographic details. As a web-based presence is necessary, ICT4SP can play a transformative role by involving the public in the way social protection programs are administered and developed.

34. The motivation to adopt front-end applications is often derived from the fact that telecommunications and internet access devices, such as mobile phones and tablets, are increasingly owned by potential beneficiaries. Where strategic partners, such as mobile telephone and payment gateway operators, are involved, they have their own software, so the costs of communicating with recipients is reduced to network bulk usage charges (e.g., SMS sending of cash coupons and food vouchers). These services also make use of "native" applications written in local languages. The input (i.e., ingress) of data on beneficiaries into local office databases is also available. The same set of wireless and internet-connected devices can be used for ingress as well as for receiving benefits. 


\section{COSTS AND BENEFITS OF ICT4SP}

35. Policies to invest in ICT4SP must be budgeted in two ways: (i) absolutely, according to the size of the budget; and (ii) relatively, according to an assessment of future costs and benefits. In the long term, the cost of ICT4SP will decline,$^{10}$ so phasing in ICT does allow for extended time frames, and can also avoid costly mistakes. A comprehensive list of key costs involved includes set-up, maintenance, upgrades, and operation; data collection, cleaning, and formatting especially from paper-based or legacy systems; cross-government agency adoption, installation, and budgets; staff skills, training costs, and resource redeployments; legality of data sharing and privacy legislation; security issues, firewalls, and detection systems; fiber-optic networks; alignment of agency subsystems for interoperability; designing and developing new user-friendly interfaces; and outreach facilities, such as e-kiosks, mobile networks, hotspots, and telecenters.

\section{Box 5: Case Study in Mongolia}

At the center of Mongolia's information and communication technology (ICT) systems is the Integrated Sectoral Database (ISDB) that uses MySQL, with 10 million household data records occupying 4.1 gigabytes, and able to serve up to 10,000 simultaneous users. The architecture and database for ISDB was developed under the Food Stamp Program from the proxy means test survey response and protocols. Various other programs in social protection, run under different ministries, use the ISDB, as it provides the means for identifying eligible households.

The Welfare Aid Information System, an ICT initiative supported by the World Bank's Multi-Sectoral Technical Assistance Project, offers welfare aid and services to over 700,000 recipients across the country applying a proxy means test to ISDB household data. ${ }^{a}$ The project development team leader sees the future need to "be improved so citizens can request welfare services on line without going to an office," and "a person enrolled in the program can create his name and account and get the services without going to a bank" (p. 36). To develop this front-end infrastructure, since 2013, Mongolia has been promoting ATM-like e-kiosks across the country (108 at the time of writing) that provide access to 21 types of government services as a one-stop shop. Electronic funds transfer systems are also in place.

The challenges Mongolia still faces include different ICT systems at various stages of development distributed across different ministries and departments, and the potential problem of upgrading systems using international standards. A specialist from the National Authority for Children identified the problem as having to be fully dependent upon local vendors for "changes and improvements to the system. Therefore, we need to improve these systems or develop new systems" (p. 29). Some agencies, such as the National Rehabilitation and Development Centre, have no integrated database of persons with disabilities, although its clinic does make use of the health sector's statistical processing $\mathrm{H}$-info system.

\footnotetext{
a A PMT uses multivariate regression analysis using household variables, such as income, health, education, etc., to identify those in most need and with few resources to help themselves. AusAid (2012) Targeting the Poor: An assessment of the proxy means test methodology. http://www.unicef.org/socialpolicy/files/targeting-poorest.pdf

Source: ADB. 2016. Regional Technical Assistance 8686 Consultant Report (Mongolia).
}

10 In 1965, Gordon Moore, the co-founder of Intel, observed that the capacity of transistors on an integrated circuit board was growing exponentially, doubling every 18 months, which implied that the costs per circuit were falling by $50 \%$ over that same period. This has become known as Moore's Law. With continuous advances in semiconductor or processor technologies, this rate of improvement has continued. Because processors are at the core of all digital electronic devices, ICT hardware and software have been falling in price and dramatically increasing in capacity since the mid-1950s. One result has been the miniaturization of devices, so today, tablets and smartphone are minicomputers, able to run multiple offline and online applications. 
36. Estimating the costs and benefits of ICT4SP differs from estimating them for a large commercial enterprise. On the cost side, the principal objective is the same: reducing the total cost of ownership, which includes capital and current costs, maintenance, and upgrades. This is especially true in a dynamic context, where increasing the scope and/or scale of the systems may be involved. However, on the benefits side, the driver in the public sector includes the quality and level of service above all other considerations, whereas in the commercial world, room for trade-offs can be greater and depends on the state of the market. For example, a lower level of service may be a trade-off for a cheaper service, but in the area of social protection, this is unacceptable unless there are alternative sources of benefits, such as the introduction of a minimum wage or an extension of private sector pensions. Not all social protection measures must be provided by the state, but the historical prevalence of the state in providing them testifies to the recurrence of market failures in providing these externalities. ${ }^{11}$

37. Delivering pensions, food stamps, cash transfers, and other welfare benefits in a timely, secure, and convenient manner is a key objective of social protection programs. Reducing costs in ways that compromise those objectives is either poor decision making or the harsh results of austerity programs.

\section{A. Supporting Infrastructure}

38. Supporting information systems through networks are internet and broadband infrastructure using a variety of technologies; ranging from ethernet links between office computers, digital subscriber lines (DSLs) linking homes and offices to the internet; fiber-optic cables connecting telecommunications systems across metropolitan, national, and international backbones; and broadband wireless connections, such as 4G LTE mobile phone and WiFi networks. Plugged into these networks is the economy and society which the administration of social protection should take full advantage.

39. Connecting to beneficiaries through mobile devices is now commonplace, and welfare benefits can be electronically paid directly into the bank or post office accounts of recipients or sent to a mobile phone's electronic wallet as a voucher or coupon to be cashed in using an ATM or exchanged at a store for food. Such direct methods of payment using payment gateways mean that payments are less likely to fall into the wrong hands, are more easily tracked and traced for monitoring and security purposes, and provide more timely and convenient methods of benefits delivery.

40. Many of these benefits resulting from the use of ICT4SP can be easily understood as qualitative benefits in making the lives of recipients easier, for example, by cutting down on travel and waiting times needed to collect benefits, and offering greater transparency of payments. If payments are automated through electronic fund transfers (EFTs), this makes it easy to track and trace digital transactions by following an audit trail for monitoring and evaluation purposes. Detecting incorrect payments saves money and reduces leakages. These can and should be quantified and fully reported.

\section{B. Databases: Transactions versus Operational Analytics}

41. Databases are at the heart of any ICT4SP system. Both conceptually and logically, databases are the hubs of management information systems and are the most expensive item. Thus, understanding databases and their architecture, which determine their scalability and role in ICT systems, is an important step toward a cost-benefit appraisal.

11 The costs of poverty relief are external to the markets themselves, hence the need for general taxation and employers' national insurance contributions. 
42. Common terminology distinguishes between databases designed for transactional purposes and data warehouses, which store large volumes of data arranged for relational or operational analysis. Data warehouses, in turn, consist of aggregated data that are stored across several localized databases or data marts. The software programs that manage the allocation and processing of data stored in data warehouses and data marts are known as relational database management systems, although the emerging trends are toward database architecture and programs that include objects as data, such as audio and video. An emerging trend is for very high-capacity and high-speed database management systems to be able to straddle both transactional and data warehouse systems.

43. Different databases are designed to store different volumes of data records in different ways. The database most appropriate for national social protection data storage, operational analytics, and reporting is a relational database that can store and process data running into terabytes or even, in a country with a very large population, petabytes. This is more likely in cases where the databases associated with different social protection programs are merged at the national level into a centralized database. The advantage of such a merger is to create a more holistic view of the needs of the poor. For example, health issues may be related to poor housing conditions, multiple children in a family, and/or unemployment. The most effective way to provide social assistance may not be detected unless a holistic approach is available.

44. Social protection programs must be able to relate hundreds of thousands, or even many millions, of different persons, and their unique identifiers (UIDs), to different data values such as addresses, ages, gender, income, employment, household size, and health indicators. The standard relational database format is a matrix series of columns and rows. The first entry in column 1 is the key, usually the name of the person or UID, and the first entry in column 2 is a value, such as gender, address, or age. Each key-value pairing is called a "tuple," which is a computer term for a data record. If there are, for example, 10 values to be related to the same person or UID, then the key will repeat itself down 10 rows in the first column, and each of the values will appear once down the same 10 rows of the second column.

45. Feedback arising from the detection of data entry errors and cases of deliberate fraud also needs to be ingested into the database for future reference so the next round of payments excludes these cases. These savings are not one-off, because without their detection, payments would be ongoing. In budgetary terms, the money saved can be reallocated, representing a real and permanent gain to society. Occasional inputs, such as deleting fraudulent cases, registering a new beneficiary, removing a decedent's name and details, and removing a duplicated entry, are known as "transactions." In contrast, ongoing and repetitive data operations, such as weekly or monthly payments to beneficiaries, are known as "operational analytics." Operational analytics involve the regular use of a database along with a generation of reports, which summarize and analyze all the above and provide forecasts and projections for administrators and policy makers.

\section{Resource Management}

46. A crucial role of any software is to manage computer resources or a computer's processing power as effectively as possible. For example, the way in which the database software stores data that are being ingested, transforms them into a standardized format, cleans them by identifying and eliminating duplicates, and retrieves them for further use, are all part of the principle of resource management. This is an important issue that runs throughout ICT systems and influences the costs and benefits of investing in ICT systems and should therefore be borne in mind when selecting ICT4SP. 


\section{Box 6: Case Study in Nepal}

For both back-end and front-end use of information and communication technology (ICT), Nepal is a good example of remote entry of data collected from households, and distribution of funds through a partnership with local banks and a local mobile payments company using two-factor authentication for security.

The Department of Civil Registration (DOCR) manages the operation of social protection programs through local bodies. DOCR runs a database, Civil Register, containing the unique identifiers (UIDs) of citizens as a registry of legal documents. DOCR also uses a management information system for the identification of beneficiaries from that database for compliance purposes, grievance relief in cases where individuals have raised queries about their entries in the database, and compilation of payment lists. It was built using Microsoft integrated development environment tools Visual Studio 2010 for graphical displays and ASP.NET for webbased applications. The cost of a license for Visual Studio 2010 was about $\$ 12,000$ for the first year and $\$ 4,000$ for annual renewals. There are no significant costs attached to using ASP.NET. These run over local, provincial, and central SQL databases supplied by Oracle and Microsoft.

Gathering and ingesting the data occurred through a house-to-house census, where data were entered into portable devices, such as tablets with pre-installed tabulation for standardized entry formatting. If an internet connection was available, the data were directly sent to the local database server; if not, the process was done offline. The management information system automatically checks for, and rejects, duplicate entries. There were 17 parameters to be matched for potential beneficiaries.

Hello PAiSA is an online payment gateway that uses the internet and interactive voice response service to process transfers within Nepal. In the relief operations following the 2015 earthquake, numerous international aid agencies worked closely with DOCR to draw up lists of UIDs of affected persons. They began using short message services (SMSs) to transfer cash and food vouchers to those in need. In addition, the Hello PAiSA system generated lists of beneficiaries, coordinating with local banks and places with point-of-sale terminals, and sent out voucher notifications followed by an SMS one-time password, which the recipient had quote in a return of the voucher notification. In a record, Hello PAiSA served 11,000 cases in 4 hours through 4 pointof-sale terminals.

Benefits include an all-digital process that reduces manual errors and deters fraud; a faster, more efficient way to disburse cash benefits; comprehensive coverage; suitable local solutions; awareness of the benefits of financial inclusion; and efficiency through its real-time monitoring and reporting systems.

Source: ADB. 2015. Regional Technical Assistance 8686 Consultant Report (Nepal).

47. Thus, when selecting an appropriate relational database system, the scale and scope of the ICT4SP toward policy goals must be determined. Two fundamental considerations are important: the human and financial resources available to manage and operate such a system; and the scale and scope of the benefits that can be offered by society, and type of reports, including monitoring and evaluation and forecasting, that are required. Thereafter, it is important to decipher when and how the systems will be upgraded and/or expanded to broaden the scope of operations. ${ }^{12}$ Other considerations include if original vendors are still in the market, or if staff training is part of the contract with the vendor.

12 For example, a 2010 paper reported a homepage message on the Government Service Insurance Scheme website of the Philippines that indicated a transition from an IBM-DB2 to an Oracle database as "currently ongoing and that this may cause some disruption to its services." A. C. Orbeta, Jr. 2010. Social Protection in the Philippines: Current State and Challenges. In M. G. Asher, S. Oum, and F. Parulian, eds. Social Protection in East Asia-Current State and Challenges. ERIA Research Project Report 2009-9, Jakarta: ERIA. 


\section{FUTURE DIRECTIONS FOR ADB IN SUPPORTING DEVELOPMENT OF ICT4SP}

48. ADB has supported close to 500 projects with ICT components between 2000 and 2012, including those that aimed to improve public services and government administration. ${ }^{13}$ ADB has been active in providing technical assistance and lending support for ICT4SP, especially in monitoring and evaluating progress and deliverables. Support for ICT4SP has also included the use of ICT for targeting, program management, beneficiary identification, benefit distribution, and monitoring.

49. At ADB, social protection comes under the public-sector management sector, which accounted for $18 \%$ of the total sector expenditures by the end of $2014 .{ }^{14}$ In the areas of health and social protection, between 2000 and 2013, ADB supported 24 ICT-related projects in nine counties (i.e., Bangladesh, Cambodia, the People's Republic of China, the Lao People's Democratic Republic, the Marshall Islands, Mongolia, Pakistan, the Philippines, and Viet Nam) and three regional initiatives. Most of the projects are in the health sector, including combatting communicable diseases, and developing management information systems in health care. Five of the projects relate to non-health care social protection programs, including developing management information systems, upgrading ICT systems, conducting ICT skills training, and creating a computerized verification system. ${ }^{15}$

50. As DMCs continue to move to expand social protection program coverage and depth, ADB support can be channeled to the use of ICT4SP to achieve greater development impact. Many social protection programs in the region remain paper-based and require in-person transactions. Several countries including Mongolia and Viet Nam have started to integrate payment solutions that make it easier for beneficiaries to interact with programs and government, without the need to travel to government offices to collect payments. A few DMCs, like Nepal, have adopted experiences of other DMCs (such as Indonesia and the Philippines) and introduced electronic or mobile phone payments and cash cards.

51. As more DMCs expand their social protection programs, opportunities to incorporate ICT components that can magnify development impacts will arise. Where social protection programs are ongoing or under consideration, integrating a component that builds ICT capacity of staff and managers of social protection programs or piloting the use of ICT elements as part of ADB-financed components could contribute to improved social protection program implementation and monitoring. Where standalone ICT projects are being considered, incorporating technology into a pilot for social services, health, social protection, and education would immediately show how citizens benefit from technologies.

52. In these potential intervention areas, capacity development will continue to be a recurring need requiring consideration. South-south learning exchanges, continuing research on applications that work and can be shared, and building a network for knowledge sharing involving the private sector (especially technology providers) are among the key activities that can support capacity development.

53. Some ICT innovations from ADB experience and case studies should be considered when providing ICT4SP support, and these are described as follows. Most build on current systems and programs in DMCs, and many are incremental in nature. When opportunities and needs exist, piloting

13 ADB. 2014. Promoting Information and Communication Technology in ADB Operations. Manila.

14 ADB. Information and Communication Technology. http://www.adb.org/sectors/ict/main

15 ADB. 2014. ICT-Related Projects by Sector/Geographic Scope Complete List (2000-2013). http://www.adb.org/sites/ default/files/adb-ict-projects-by-sector.pdf 
of new technologies can be beneficial due to the high potential for replicating these in other countries. Some examples of interventions that can be supported by ADB going forward can include:

- Paperless systems. Simple administrative fixes and solutions that can improve ongoing programs are among the easiest to support, building on what is already in place incrementally. These solutions can include going paperless, especially in reporting, registration, and enrollment of beneficiaries. Introducing online reporting and transmission of reports online can shorten transmission time. Digitization of records can also be prioritized to allow for online services. Common ways of digitization include web-based applications that offer web interfaces for electronic forms that users can provide electronically, scanning and recognition to digitize paper documents, or electronic signatures for digital documents.

- Electronic payments. These not only free up human resources from doing manual cash transactions but also introduce a transparent manner of managing payments that can be tracked. Most DMCs already have in-country facilities that allow for EFTs, the most common of which are online banking and electronic cash. Although in times of emergencies these services are usually offered for free by mobile network operators, to use them on an ongoing basis requires commercial arrangements perhaps through public-private partnerships or on a market-led contractual basis where the mobile network operator sends out vouchers from a list provided by the authorities.

- Mobile money. Mobile phone-based financial services transform traditional cash services into cashless transactions. Any commercial organization can provide mobile money services; however, the most common providers are telecommunications service providers or joint ventures between a telecommunications service provider with a credit services provider. As mobile phone services become more widely used, people will likely prefer mobile phone services than banking services, because of wider coverage, easier access, and more familiar utilization.

- Authentication and verification using biometrics and smartphones. Online biometric authentication, through fingerprints, can be used to take the place of in-person authentication. A built-in fingerprint scanner captures a digital image of fingerprints and stores this as the fingerprint pattern of owners or users.

- Smartcards. Smartcards are attractive but costly, given the need to provide card readers to all potential places where services or goods can be secured, like medical centers, social protection offices, and merchants. A multifunction smartcard can, however, make them cost-effective for social protection programs. In Viet Nam, for example, a card can contain biometric information for identity authentication; the participant's contribution history in lieu of the social protection notebook; information on his or her health insurance card; his or her health records and treatment credentials; user identity for banking services; money for payment; and money transfer.

- Capacity-building support. Among the areas identified as having contributed to a slow uptake of ICT in social protection programs is the low appreciation, both of social protection agency staff and beneficiaries (especially the elderly and those residing in geographically challenging areas) of ICT. In Viet Nam, while the infrastructure for EFTs and mobile money exist, cash-based transactions are still more common because of general unfamiliarity with the technologies of cashless transfers. In Mongolia, staff's understanding of ICT development has not kept pace with rapid changes in technology. An area of potential support is the continuation of knowledge sharing and hands-on exchanges among DMCs to see what works first-hand. 


\section{REFERENCES}

ADB. 2014a. Promoting Information and Communication Technology in ADB Operations. Manila.

_.2014b. Social Protection Operational Plan, 2014-2020. Manila.

2014c. ICT-Related Projects by Sector/Geographic Scope Complete List (2000-2013). http:// www.adb.org/sites/default/files/adb-ict-projects-by-sector.pdf

. 2015. Stock Taking of ICT Use in SP in Nepal; S. Lang. 2010. It's Official: VS 2010 Branding and Pricing. Microsoft. 26 January. http://blogs.msdn.com/b/slange/archive/2010/01/26/it-s-officialvs-2010-branding-pricing.aspx

AusAid. 2012. Targeting the Poor: An assessment of the proxy means test methodology. http://www.unicef. org/socialpolicy/files/targeting-poorest.pdf

International Social Security Association. 2017. ISSA Guidelines: Information and Communication Technology. https://www.issa.int/en/details?uuid=99ac53ba-36c7-4386-87de-6e6854cd6631

McKenna, B. 2013. What Does a Petabyte Look Like? Computer Weekly.com. http://www.computerweekly. $\mathrm{com} /$ feature/What-does-a-petabyte-look-like

Misuraca, G., C. Colombo, R. Radescu, and M. Bacigalupo. 2015. ICT-Enabled Social Innovation in Support to the Implementation of the Social Investment Package - IESI. European Commission JRC Science and Policy Report. http://publications.jrc.ec.europa.eu/repository/bitstream/JRC97467/ jrc97467.pdf

Orbeta Jr., A.C. 2010. Social Protection in the Philippines: Current State and Challenges. In M. G. Asher, S. Oum, and F. Parulian, eds. Social Protection in East Asia-Current State and Challenges. ERIA Research Project Report 2009-9, Jakarta. 


\section{Improving the Delivery of Social Protection through ICT}

\section{Case Studies in Mongolia, Nepal, and Viet Nam}

This working paper makes a case for investing in ICT to improve the delivery services of social protection programs. ICT for social protection will improve efficiency, transparency, and empower citizens by opening up areas of information and social engagement that can influence policies and resources devoted for social protection.

\section{About the Asian Development Bank}

ADB's vision is an Asia and Pacific region free of poverty. Its mission is to help its developing member countries reduce poverty and improve the quality of life of their people. Despite the region's many successes, it remains home to a large share of the world's poor. ADB is committed to reducing poverty through inclusive economic growth, environmentally sustainable growth, and regional integration.

Based in Manila, ADB is owned by 67 members, including 48 from the region. Its main instruments for helping its developing member countries are policy dialogue, loans, equity investments, guarantees, grants, and technical assistance. 